\title{
Late Stillbirth
}

National Cancer Institute

\section{Source}

National Cancer Institute. Late Stillbirth. NCI Thesaurus. Code C120585.

Delivery of a dead fetus greater than 28 weeks gestational age and/or greater than 1,000 grams birth weight. 